\title{
Deep Mantle Fluids and Their Products Products in Kimberlites from China
}

\author{
ZHAO Lei ${ }^{1}$, ZHANG Peiyuan ${ }^{2}$, HUANG Xiang ${ }^{1}$ and LI Youzhi ${ }^{1}$ \\ 1. China University of Geosciences (Beijing, 100083) \\ 2. Ministry of Geology and Minereal Resources, P. R. China
}

On the basis of the observation and research of petrography, mineralogy. and mineral chemistry, The behavior of deep fluids and their products in kimberlites and diamonds fall into three forms : ultradeep fluid transmitted minerals, deep fluid metasomatized minerals and deep fluid reformed minerals, with a successive descent at fluid origin depth. metasomatism strength as well as a series of corresponding different metasomatism forms (Zhao, 1996).

\section{Ultra Deep Fluid Transmitted Minerals}

Ultradeep pressure experiments, geophysical data and rare inclusions in diamonds have been deepened into seismic discontinuity, 670 kilometers beneath the Earths surface (Harte, et, al 1994). Very likely, most of siderophile elements, such as $\mathrm{Fe} \mathrm{Ni} \mathrm{Co,} \mathrm{Cu,} \mathrm{W,} \mathrm{As,} \mathrm{Ge} \mathrm{Ag}$ and $\mathrm{Au}$ are components of the core (Haggety, 1994). The authers name the materials ultradeep fluid transmitted minerals with the same elements joined core- mantle differentiation; The characteristic of the elements are strong reduction, and a far higher formation temperature than those in kimberlite magma. with the delivery and participation of ultradeep fluid, they enter kimberlite magmas and diamonds then reach or nearly reach the surface of the Earth. These minerals include: $\mathrm{WC}, \mathrm{WC}_{2}$, native silicon, native iron and their interactants native silver and Ag-bearing iron- gold alloy inclusions (Zhao, et, al, 1995) .

In a word, they are all special minerals, simple substances and their analogous minerals relating to the uletradeep fluid in kimberlites and diamonds, they make a feature of oxygenfree, therefore, they are of the significant symbols of ulradeep and very strongly reduing environment.

\section{Deep Fluid Metasomatized Minerals}

All of the characteristics of composition, reduction-oxidation state, deformation, and occurrence of deep fluid metasomatized minerals indicate that they are not the products of kimberlite magmatic crystallization but mantle materials. Rich in $\mathrm{TiO}_{2}, \mathrm{~K}_{2} \mathrm{O}, \mathrm{Na}_{2} \mathrm{O}, \mathrm{BaO}$ and REE, which are all characteristic compositions of mantle metasomatic fluid, they have experienced a series of metamorphism and deformation processes. The main minerals are as the follows : Lindsleyite, Mathiasite. Yimengite and $\mathrm{Na}-\mathrm{Si}$-rich orthopyroxene and so on. The element of $\mathrm{Fe}$ in these minerals shows itself by way of $\mathrm{Fe}^{3+}$, the deep mantle reaction related to $\mathrm{Fe}$ shows : $3 \mathrm{Fe}^{2+} \rightarrow$ $2 \mathrm{Fe}^{3+}+\mathrm{Fe}^{\circ}, \mathrm{Fe}^{3+}$ is transported upward by deep mantle fluid in deep mantle, combines itself

*Supported by the National 305 Project Office of China 
with $\mathrm{Cr}, \mathrm{Mg}$ of mantle and forms metasomatism minerals at the same time. the $\mathrm{Fe}^{\circ}$ in the equation is carried to the core and is accumulated there. During this course, native iron occur in kimberlites and in diamonds as inclusions.

The appearance of this kind of minerals indicates that compositions and character of mantle fluids have been notablely changed, varying from oxygen-free or oxygen- deficient fluids, ultradeep and rich in metal elements fluid, to oxygen bearing fluid rich in $\mathrm{Ti}, \mathrm{K}, \mathrm{Na}, \mathrm{Ba}$ and REE. At the same time, the changed fluids metasomatize with mantle materials and bring forth metasomatism minerals.

\section{Mantle Fluid Reformed Minerals}

Mantle fluid reformed minerals mean that the mantle-featured minerals whose compositions have been changed to some extent by mantle fluid but still remain stable in the mantle They include phlogopite, pyrope, chromite, olivine Pyroxene and so on. Among them the hydrous ones contain extra structure $\mathrm{H}_{2} \mathrm{O}$ and depicient in $\mathrm{SiO}_{2}$. On the other hand, the theoretically anhydrous ones contain $\mathrm{H}_{2} \mathrm{O}$, such as olivine, pyroxene.

Of them, mantle olivine (peridotite and macrocrysts) might be serpentinized strongly or completely by the shallow mantle fluid. Lizardites are dominant among mantle xenoliths, while the majority of macrocrystals are antigorites. Lizardites are formed in neutral medium, but antigorites grow in alkali medium after the formation of lizardites. Olives in xenoliths and macrocrysts give birth to different kinds of serpentins, as indicates that serpentinization of peridotite xenoliths has atready begun while or before the xenoliths come into kimberlites magmas, mantle fluids of that time are neutral and that the macrocrysts are further altered to antigorites by the atkali medium, mixed fluids made from mantle fluids and kimberlites own fluid.

Theoretically, the ultradeep fluids should be at last come from the core-mantle boundary. However, though the crystallizatin temperature of WC up to $2765 \mathrm{C}$, nearly equal to that of the core, there are not adequate evidences to confirm that it is the material that comes from the core.

From bottom to top, mantle deep fluids can be divided into oxygen-free (or oxygen-deficient) ultradeep fluids; deep oxygen-bearing fluids rich in $\mathrm{Ti}, \mathrm{K}, \mathrm{Na}, \mathrm{Ba}$, and REE; water-rich alkali fluids evolved from the above two kinds.

The represntatives of oxygen-free (or oxygen-deficient) ultradeep fluid are natural elements and or their similarities, for example, $\mathrm{Au}, \mathrm{Ag}, \mathrm{Cu}, \mathrm{Fe}, \mathrm{Zn}, \mathrm{Sn}, \mathrm{Pb}, \mathrm{W}, \mathrm{S}$, transported by ultradeep fluid.

In the area affected by this kind of fluid, it is characteristic that the deeper, the richer of Fe content there is.

Deep oxygen-bearing fluid interact on $\mathrm{Cr}$, $\mathrm{Mg}$-rich solid mantle materials, forms minerals in which big radius cations coexist with small radius ones stably, as a symbol of high pressure. 
Nearly all of $\mathrm{Fe}$ exist by way of $\mathrm{Fe}^{3+}$, reflecting a oxidization character. The division plane between the two fluids is the place where wuestite exists stably.

Water-rich alkali fluid evolves on the basis of the former fluids, with a character of waterrichness. The main behavier is to reform mantle stable rock-forming minerals, ending up with the appearance of antigorites. Under the effect of these fluids, cubic diamonds, diamend coatings and microgranular diamonds come into being, containing probably inclusions of $\mathrm{kCl} \mathrm{NaCl}$, calcite, feldspar, $\mathrm{CuCl}_{2}$ and so on.

\section{References}

Haggerty S. E.. 1994, Super kimberlites, Earth and Planetary Science Letter, 12 : 57-96

Harte. B, et, al. 1994, Lower mantle mineral associations preseved in diamonds, Mineralogical Magzine, V.58A, 9. 384-385.

Zhao Lei, 1996, Mantle Source Material from Kimberlite and Inclusions in diamonds, In : Du Letian edited, Mantle Fluid and Asthenospheric Layer Geochemical, P. 137-147 (in chinese) Geological Press.

Zhao Lei, et, al, 1995, The first discovery of native silver and silver-bearing Fe-Au alloy inclusions in diamonds, Chinese Science Bulletin, V. 40, N. 12, P. 1114-1115. 